\title{
Signal Transduction by Type I Interferons
}

\author{
Michael David \\ Division of Biological Sciences, and UCSD Cancer Center, University of California, San Diego, CA, USA
}

BioTechniques 33:S58-S65 (October 2002)

\begin{abstract}

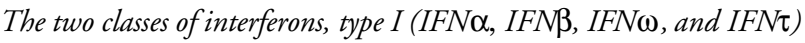
and type II (IFN $\gamma$ ) are pleiotropic cytokines that exhibit antiviral, antiproliferative, and immunomodulatory effects on their target cells. This article summarizes the advances made in elucidating the molecular events that mediate the biological responses to type I interferons.
\end{abstract}

\section{INTRODUCTION}

The interferons (IFNs) are a family of cytokines that exhibit pleiotropic intracellular effects generally categorized into antiviral, antiproliferative, and immunomodulatory roles $(46,73)$. First isolated as agents of antiviral activity, the IFNs were later subdivided into two classes based on structural and functional differences (37). The type I IFNs include IFN $\alpha$ and IFN $\beta$, which are produced by leukocytes and fibroblasts, respectively, as well as IFN $\omega$ and IFN $\tau$. In contrast, the only type II IFN, IFN $\gamma$, is produced by CD8 ${ }^{+} \mathrm{T}$ cells, CD4+ Th0 and Th1 cells, and natural killer (NK) cells. The goal of this article is to summarize the recent findings in the signal transduction pathways initiated by type I IFNs.

\section{TYPE I INTERFERONS AND THEIR ACTIONS}

The major representatives, IFN $\alpha$ and IFN $\beta$, are both 4- $\alpha$ helical bundle cytokines that bind to a common cell surface receptor. Fourteen human genes and 4 pseudogenes have been identified for IFN $\alpha$, although the consequences of the existence of these multiple gene products remains elusive. Conversely, IFN $\beta$ is a single gene product exhibiting 13\%-30\% similarity to the IFN $\alpha$ protein products and is thought to have arisen by gene duplication and gene conversion of the IFN $\alpha$ locus. The IFN $\alpha$ and IFN $\beta$ loci lie adjacent to one another on human chromosome 9 and murine chromosome 4 and share a similar intronless gene structure (reviewed in Reference 74).

Most cells have the capability of synthesizing type I IFNs in response to viral infection or following contact with doublestranded RNA (dsRNA). Upon viral infection, biosynthesis of the type I IFNs is rapid, as their extracellular presence can be detected within 6 hours following infection.

Type I IFNs stimulate the synthesis of several antiviral gene products such as the $2^{\prime}-5^{\prime}$ oligoadenylate synthetase. This enzyme is activated by the presence of dsRNA, a viral replication intermediate, to polymerize ATP into $2^{\prime}-5^{\prime}$ oligomers. The oligomers, in turn, activate RNAse L, a constitutively expressed single-stranded RNA (ssRNA) ribonuclease, thereby inhibiting viral RNA production and viral protein synthesis. Protein kinase $\mathrm{R}$ (PKR), a serine/threonine kinase is also induced by IFN $\alpha / \beta$. PKR phosphorylates the eIF-2 elongation factor, inhibiting its activity and disrupting protein translation (100).

The growth inhibitory effects of type I IFNs have been well documented, though many mediators responsible for the antiproliferative action of IFNs remain undefined. Various growth-modulating factors have been implicated in this process $(22,42,58)$, and the elucidation of the IFN antiproliferative pathways has been hampered by the inconsistencies between cell systems. While the IFN-mediated induction of IRF-1, a documented tumor suppressor $(103,104)$, appears to be a ubiquitous event, the modulated expression or posttranslational modification of several cell cycle control proteins such as cyclin D3, p27kip, phosphoRb, and c-myc $(42,106,117)$ in response to interferon stimulation varies between cell types or cell lines.

IFNs also induce intracellular processes, which modulate the host immune response to infection. For instance, upregulated expression of major histocompatibility complex (MHC) class I molecules in response to type I IFNs increases presentation of viral antigens on the surface of virally infected cells and targets them for cytotoxic CD8 ${ }^{+} \mathrm{T}$ cell activity (100).

\section{TYPE I INTERFERON RECEPTOR}

IFNs initiate their biological effects by binding to their respective cognate cell surface receptors. All type I IFNs bind to a common receptor (IFNAR), whereas IFN $\gamma$ utilizes a distinct receptor, IFNGR, both of which are ubiquitously expressed. Similar to other cytokine receptors, the IFN receptors display a high degree of species specificity in ligand recognition (73).

The type I IFN receptor exists as a multichain structure composed of IFNAR1 ( $\alpha$-subunit) (114) and IFNAR2 ( $\beta$-subunit) $(19,70)$. Both chains, each encoded by a distinct gene localized on human chromosome 21q22.1, exist as two membranebound splice variants. The $110-\mathrm{kDa}$ IFNAR1 alone only binds one species of IFN $\alpha$ (IFN $\alpha$ B2), but is required for signaling by all type I IFNs. A short splice variant, IFNAR1s, lacks the extra- 
cellular subdomain encoded by exons 4 and 5 of the IFNAR1 gene, rendering the receptor insensitive to IFN $\alpha \mathrm{B} 2$ and IFN $\alpha$ F, while binding of IFN $\alpha A$ and IFN $\omega$ is maintained (reviewed in Reference 74). Alternative processing of the IFNAR2 RNA also yields two related proteins. The long $100-\mathrm{kDa}$ IFNAR2c in a complex with IFNAR1 results in a fully functional type I IFN receptor $(19,70)$. In contrast, expression of the short, cytoplasmic truncated form, IFNAR2b, in IFNAR2-deficient cells generates a low affinity binding site but no functional receptor (56). Interestingly, only IFN $\beta$, but not IFN $\alpha$, stimulation allows for the co-immunoprecipitation of IFNAR1 with IFNAR2c (78). This unique response transcends into the specific activation of the $\beta R 1$ gene by IFN $\beta$ (82). These results demonstrate the different type I IFNs utilize distinct sites for interaction with the IFN $\alpha / \beta$ receptor, and that only a complex of IFNAR 1 and IF-
NAR2c is capable of mediating the biological effects of all members of the IFN $\alpha / \beta$ family (Figure 1 ).

\section{SIGNAL TRANSDUCERS AND ACTIVATORS OF TRANSCRIPTION (STATs)}

Identification of IFN-induced RNAs and analysis of the promoters of IFN $\alpha / \beta$-stimulated genes led to the identification of an enhancer termed the interferon stimulated response element (ISRE), which proved necessary and sufficient for activation of these genes by IFN $\alpha / \beta(48,49,86,87)$. Binding of IFN $\alpha / \beta$ to its receptor activates the latent cytoplasmic transcription factor complex interferon stimulated gene factor 3 (ISGF3) $(25,39$, 50 ), whose nuclear translocation and binding to the ISRE is re-

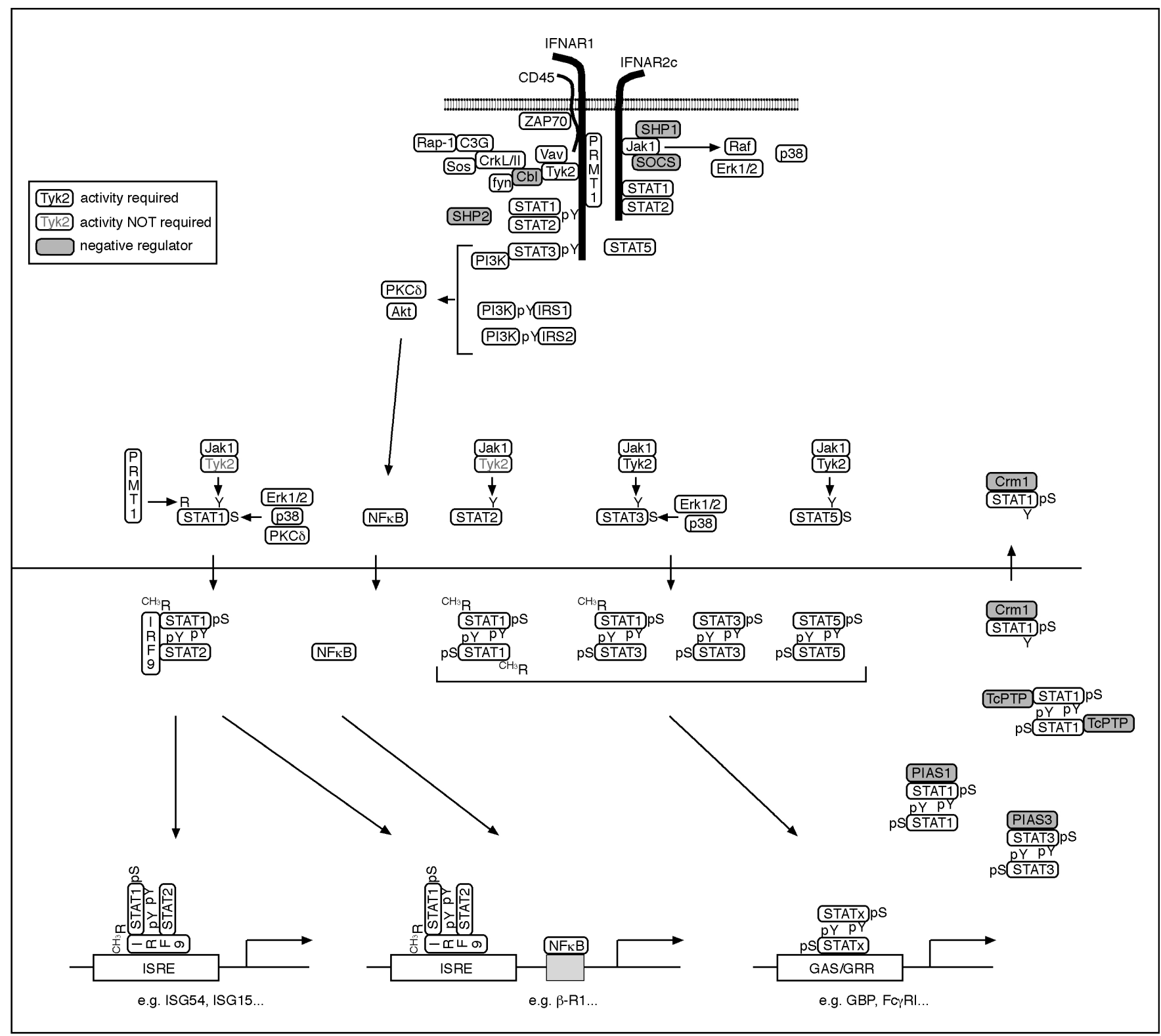

Figure 1. Signaling pathways activated by the type I interferon receptor. 


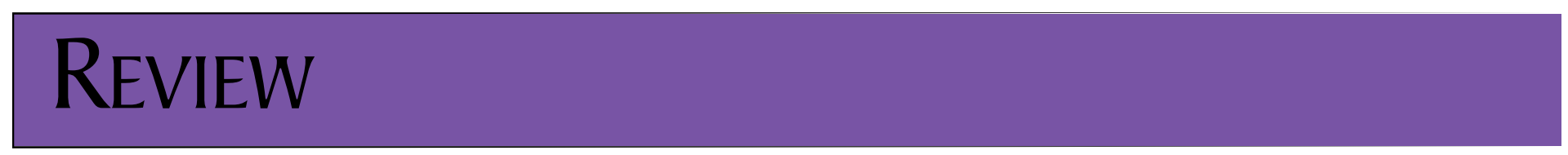

quired for the activation of early response genes by type I IFNs. The SH2-domain containing proteins STAT $1 \alpha$ (formerly p91), its splice variant STAT1 $\beta$ (formerly p84), and STAT2 (formerly p113) were identified as the regulatory components of the ISGF3 complex $(26,27,91)$. In contrast, IRF9 (formerly p 48 , ISGF3 $\gamma$ ) functions independently of IFN $\alpha / \beta$-induced posttranslational modification as a DNA adapter molecule $(14,50,51)$. Studies into the activating mechanism revealed that the IFN $\alpha / \beta$-induced formation of ISGF3 requires the phosphorylation of Tyr701 in STAT1 and Tyr690 in STAT2, such that they can form heterodimers via their SH2 domains $(14,90,95$, 96). IFN $\alpha / \beta$ as well as IFN $\gamma$ also promote the formation of STAT1 homodimers, which bind the gamma response region (GRR) or IFN $\gamma$ activation sequence (GAS) $(52,71)$ in genes such as IRF-1 (31). The development of a cell-free system where IFN $\alpha / \beta$-stimulated STAT binding to the ISRE or GAS was reenacted in either cell homogenates or partially purified plasma membranes provided evidence that the pre-associated signaling cascade is localized to the plasma membrane $(12,14)$.

The subsequently identified family members STAT3, STAT4, STAT5a, STAT5b, and STAT6 also contain SH2 domains and a conserved tyrosine in their carboxy terminus, which is phosphorylated upon incubation of cells with the appropriate cytokine $(44,45)$. Interestingly, while the tyrosine phosphorylation of STAT 1 and STAT 2 in response to IFN $\alpha / \beta$ occurs in all non-transformed cells, the type I IFN mediated tyrosine phosphorylation of STAT3, STAT4, STAT5, and STAT6 takes place in a more cell-type-specific manner $(9,23,59,88)$.

Although tyrosine phosphorylation and an intact $\mathrm{SH} 2 \mathrm{do}-$ main are essential for STAT dimer formation and activity $(26,28,96)$, other regions of STAT1 have also been implicated in the regulation of its transcriptional activity. A domain required for STAT1 to bind DNA has been localized between residues 400 and 500 (36). Under circumstances where adjacent DNA binding sites are present in a promoter, STATs can also form multimers (118). Recently the crystal structure of tyrosine phosphorylated STAT1 bound to DNA has been elucidated (7). In addition to Tyr701, the phosphorylation of Ser727, located within the carboxyl terminus of STAT1 in a consensus MAP kinase phosphorylation site is required for robust transcriptional activity $(16,116)$. STAT1 $\beta$, which lacks the Ser727 containing C-terminal 38 amino acids of STAT $1 \alpha$ is unable to completely reconstitute IFN-stimulated STAT1-mediated gene transcription (6).

Although the IFNs have been shown to activate several STAT family members, STAT1 activation is probably the most significant. The importance of STAT1 in interferon signaling has been demonstrated in different systems. First, the development of IFN-resistant cell lines by chemical mutagenesis demonstrated the prerequisite for STAT1 expression to convey the antiproliferative and antiviral effects of IFN (65). Further, STAT1 knockout mice appear to develop normally, but rapidly succumb to opportunistic viral infections due to an inability to respond to the type I and type II IFNs $(21,60)$.

\section{JANUS KINASES}

As both the type I and type II IFN receptors lack intrinsic kinase domains, they require the association with a family of non- receptor tyrosine kinases known as the Janus kinases (Jaks) to facilitate the tyrosine phosphorylation of STAT proteins (100). Of the four mammalian Jak kinase family members, which share highly conserved regions including a pseudokinase domain located adjacent to the tyrosine kinase domain, Jak1, Jak2, and Tyk2, are ubiquitously expressed, whereas Jak 3 expression is primarily restricted to hematopoietic cells (38).

The selection of cell lines defective in IFN $\alpha / \beta$ signaling allowed for the reconstitution of IFN $\alpha$ signaling in these lines with cDNAs encoding the defective proteins (72). The first such IFN $\alpha$ signaling defective mutant (U1) was rescued by complementation with a cDNA encoding the protein tyrosine kinase Tyk2 (115). In a similar manner, Jak1 was identified as the second Jak tyrosine kinase that is required for signaling via the type I receptor (66). Subsequent studies revealed that Tyk 2 associates with IFNAR1 and mediated its tyrosine phosphorylation, whereas Jak 1 performs this function on IFNAR2c $(11,20)$. The tyrosine phosphorylation of the receptor by the preassociated Jak kinases presumably creates the docking sites for the $\mathrm{SH} 2$ domains of the STAT proteins. Indeed, $\mathrm{SH} 2$ domain-swapping experiments indicate the $\mathrm{SH} 2$ domains of the individual STAT molecules determine the specificity in the phosphotyrosine interaction both at the receptor and between the STATs themselves (33). Nevertheless, this simplified model is complicated by the findings that STAT2 and STAT3 bind to IFNAR1 in a ligandand IFNAR1 tyrosine phosphorylation-dependent manner, whereas the association of STAT1 and STAT2 with IFNAR2c occurs independent of IFN $(53,67)$. Interestingly, STAT1 activation by IFN $\alpha / \beta$ is dependent on the presence of STAT2, which interacts with IFNAR2c outside its SH2 domain $(47,53)$.

Although several STATs are activated in response to IFN $\alpha / \beta$, they seem to be activated by distinct mechanisms. The use of specific tyrosine kinase inhibitors as well as genetic approaches demonstrated that IFN $\alpha / \beta$-mediated tyrosine phosphorylation of STAT3 and STAT5 requires the kinase activity of Tyk2, while the presence of an inactive Tyk2 protein suffices to achieve tyrosine phosphorylation of STAT1 and STAT2 and subsequent gene induction $(83,101)$.

\section{ATTENUATION OF JAK/STAT SIGNALING}

Of equal importance to the activation of a signaling pathway is its spatially and temporally coordinated attenuation. Several independent mechanisms are responsible for the negative regulatory control over the Jak/STAT pathway. The two SH2-domain containing tyrosine phosphatases SHP- 1 and SHP-2 are at least in part responsible for modulating the IFN $\alpha / \beta$ activation of the Jak/Stat pathway. SHP1 is associated with IFNAR1 and suppresses activation of the IFN $\alpha / \beta$-induced Jak1 kinase (15). Contradicting reports exist on the role of SHP 2 in IFN $\alpha / \beta$ mediated STAT activation. Expression of dominant-negative SHP2 mutants inhibits IFN $\alpha$-mediated gene induction (17), whereas the absence of SHP2 in gene-targeted animals leads to an enhanced interferon response (121).

The existence of a nuclear tyrosine phosphatase that inactivates STAT1 has been described by several labs $(13,32)$. This crucial attenuator of the interferon response was recently identified as the nuclear $45-\mathrm{kDa}$ isoform of TcPTP (105). 
The SH2-domain containing suppressor of cytokine signaling (SOCS, also known as CIS) proteins have been identified as a family of seven cytokine-inducible inhibitors of the Jak/STAT pathway $(8,34)$. These proteins bind to either tyrosine phosphorylated receptors or activated Jak kinases and mediate their ubiquitin-dependent degradation (40), thereby inactivating these essential signaling components in a classical negative feedback loop. A ubiquitin-proteosomal degradation pathway for STAT1 has also been suggested as an attenuation mechanism of the IFN activated Jak/STAT pathway (41).

In contrast to the cytokine-inducible SOCS proteins, the constitutively expressed PIAS proteins do not prevent the phosphorylation of STAT proteins, but exert their negative regulatory role by association with tyrosine phosphorylated STAT dimers and preventing them from binding DNA $(10,54)$. Recently, PIAS proteins have been shown to perform additional functions by acting as SUMO E3-ligases for c-jun and p53 $(43,92)$.

\section{STAT NUCLEAR TRANSLOCATION}

Signal-induced movement of STAT1 into the nucleus is clearly necessary for its function as a transcription factor. Ligand-induced tyrosine phosphorylation as well as an intact SH2-domain are necessary for nuclear import (62), and tyrosine phosphorylated STAT1 rapidly accumulates in the nucleus within 30 minutes of initial receptor activation. Sekimoto et al. demonstrated that microinjected anti-Ran antibodies, as well as the expression of mutant Ran proteins inhibit nuclear import of tyrosine phosphorylated STAT1 even though STAT1 contains no recognizable classical NLS motif (93). The importin- $\alpha$ homologue NPI-1 interacts with tyrosine phosphorylated STAT1, but does so via a region distinct from its classical NLS binding site. These observations indicate STAT1 nuclear import is an energy-dependent process that relies on induced recognition of STAT1 by nuclear import factors (94).

Additionally, several labs demonstrated relocalization of nuclear STAT1 molecules to the cytoplasm following interferon treatment, indicating the existence of a nuclear export mechanism. Indeed, three leucine-rich nuclear export sequences (NES), which are recognized by the export receptor Crm1, were mapped in STAT1 $(4,57,63)$, and nuclear export of STAT1 appears to be regulated in a Jak1-dependent manner, albeit independent of STAT1 tyrosine phosphorylation (63).

\section{STAT INTERACTIONS}

Using the IFNAR1 cytoplasmic domain as bait in a yeast two hybrid screen, Abramovich et al. demonstrated the association of a protein arginine methyl-transferase (PRMT1) with the IFN $\alpha / \beta$ receptor (1). Using antisense oligos to quench endogenous PRMT1 expression, it was shown that the loss of PRMT1 expression led to an inability to respond to the antiproliferative effects of IFN $\alpha / \beta$. Further experiments implicated PRMT1 in the antiviral effects of IFN $\alpha / \beta$, while similar experiments demonstrated no effect on IFN $\gamma$ activity, suggesting a specificity for PRMT1 in type I IFNs but not in type II IFN signaling (2). PRMT1 is a type I arginine methyltransferase that catalyzes the formation of $\mathrm{NG}$-monomethylarginine and asymmetric

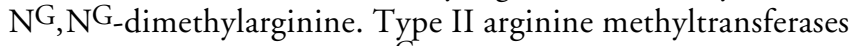
catalyze the formation of $N^{G}$-monomethylarginine and symmetric $\mathrm{NG}^{\mathrm{N}} \mathrm{N}^{\prime} \mathrm{G}_{\text {-dimethylarginine. }}$

Recently, the NH2-terminal domain of STAT1 was identified as the target for PRMT1-catalyzed protein methylation (64). Arg31, which is highly conserved between all mammalian STAT proteins, requires methylation to support IFN $\alpha / \beta$-mediated gene transcription. Inhibition of STAT 1 arginine methylation promotes its association with PIAS1, thereby preventing STAT1 from binding ISRE or GRR elements. Additional evidence for arginine methylation in IFN signaling is the recent cloning of Jak binding protein (JBP1) isolated in a yeast twohybrid screen with Jak2 (81). Capable of binding all mammalian Jaks, JBP1 has homology to the conserved regions of protein arginine methyltransferases and is the first identified type II arginine methyltransferase (81).

Interaction with the replication factor MCM5 is enhanced with Ser727 phosphorylation, and transient expression of MCM5 augments STAT1-induced transcription in a Ser727dependent manner (122). STAT1 also interacts with the transcriptional coactivator Creb binding protein (CBP). Interaction with CBP enhances STAT1 transcriptional activity. The STAT1 $\mathrm{NH} 2$-terminus interacts with the Creb binding domain (KIX) of CBP, while the STAT1 COOH-terminus associates with the $\mathrm{C} / \mathrm{H} 3$ domain, the same region of CBP that binds the E1a adenovirus protein (35). As such, competition for CBP interaction provides a mechanism for adenoviral suppression of STAT1 function (55). The coiled-coil domain of STAT1 was found to associate with an $\mathrm{N}-\mathrm{Myc}$ interactor $(\mathrm{Nmi})$ and this interaction was found to enhance CBP coactivator binding to STAT1 and, thus, augment STAT1 mediated transcription (123).

\section{ADDITIONAL SIGNALING CASCADES IN THE TYPE I IFN RESPONSE}

Several reports indicate that IFNs can activate many signaling cascades that are distinct from the Jak/Stat pathway. Numerous proteins undergo rapid tyrosine phosphorylation following exposure of cells to IFN $\alpha / \beta$. Two members of the insulin receptor substrate (IRS) family of adapter proteins, IRS-1 and IRS-2, become tyrosine phosphorylated in response to type I IFNs, allowing for the SH2-domain mediated binding of the $\mathrm{p} 85$ regulatory subunit of PI-3 kinase $(79,107)$. Interestingly, PI-3 kinase association with the IFN receptor can presumably also occur in a STAT3-facilitated manner (76). While the resulting activation of PI-3 kinase promotes the activity of the proto-oncogene Akt (PKB) $(69,112)$ and PKC $\delta$ (113), the biological consequences of these events are still unclear. Although PI-3 kinase activity is not required for ISGF3 formation or induction of ISRE-controlled genes, both STAT3 and PI-3 kinase have been proposed to be essential for the antiproliferative effects of IFN $\alpha / \beta$ (119). These findings, however, are contradicted by the observation that deletion of the STAT3/PI-3 kinase interaction domain of IFNAR1 yields a receptor with enhanced biological activity (29).

Two additional adapter proteins, both of which associate constitutively with $\mathrm{Tyk} 2$, undergo rapid tyrosine phosphorylation after IFN $\alpha / \beta$ stimulation and alter the IFN response. In 


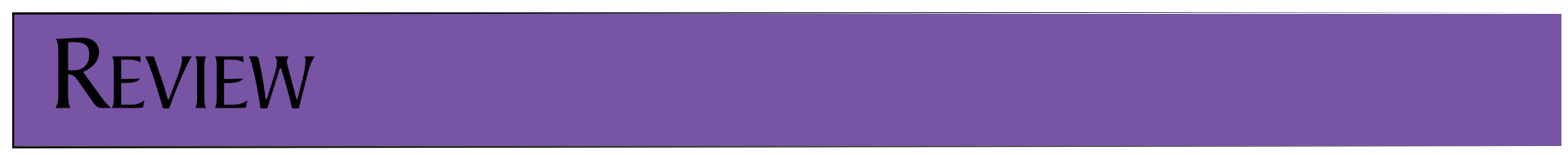

hematopoietic cells, disrupted expression of the guanine nur cleotide exchange factor Vav abrogates the growth inhibitory ef fects of IFN $\alpha(61,77,110)$. The proto-oncogene c-Cbl modulates IFN signaling in two distinct ways. In unstimulated cells, c-Cbl was reported to regulate the basal expression levels of STAT1 (5). As a target for IFN-mediated tyrosine phosphorylation (108), c-Cbl provides docking sites for the src family kinase fyn (109) as well as the adapters CrkL and CrkII $(3,18,85)$. These $\mathrm{SH} 2$ and $\mathrm{SH} 3$ domain containing proteins link c-Cbl to Sos and C3G, a guanine nucleotide exchange factor for Rap-1 $(97,102)$. CrkL can associate with STAT5 and form a GASbinding complex (24), and expression of CrkL and CrkII is essential for the antiproliferative effects of IFN $\alpha / \beta(80)$. The importance of two components of the $T$ cell receptor complex in IFN $\alpha / \beta$ signaling was illustrated by the finding that $T$ cells deficient in either ZAP70 or CD45 fail to produce a growth inhibition after exposure to IFN $\alpha / \beta$, despite appropriate activation of the Jak/STAT pathway (75).

Another signaling cascade regulated by IFNs is the MAP kinase pathway (16). IFN $\alpha / \beta$ activates Raf- 1 as well as B-Raf, two serine kinases ultimately responsible for the activation of p42MAP kinase, in a Jak1-kinase and STAT1-dependent manner $(89,98,99)$. Likewise, it has also been reported that the p38 SAPK is activated by IFN $\alpha / \beta(30,111)$. Ser 727 of Stat 1 , which is conserved in Stat 3 and Stat 4 , is positioned within a consensus phosphorylation site for proline-directed serine kinases such as MAP kinases (116). However, as other IFN $\alpha / \beta$ activated kinases, such as PKC $\delta$ (113) or the IFN $\gamma$-activated CamKII (68), also have the ability to phosphorylate Ser727 of STAT1 in vitro, it remains unclear which kinase is ultimately responsible for the phosphorylation of STAT1 Ser727 in vivo.

The exact consequences of IFN $\alpha / \beta$ treatment with regards to nuclear translocation and DNA binding of NFKB are still unclear. A recent study proposed a specific requirement for NFKB activation in the IFN $\beta$-mediated induction of the $\beta R 1$ gene (84). However, Yang et al. reported NFKB activation and concomitant cell survival through both IFN $\alpha$ and IFN $\beta$ (120). Thus, it appears that NF $\kappa B$ activation by IFNs occurs in a celltype-specific manner or that additional factors account for the IFN $\beta$-specific activation of the $\beta R 1$ gene.

Since its discovery, the Jak/STAT pathway has been the center of attention for investigations into the biological effects of type I IFNs. Significant advances in the field over the past decade have led to a broad, albeit incomplete, picture of this signaling cascade. More recent work has now, once again, aimed to characterize Jak/STAT-independent or cooperative IFN-induced signal transduction pathways. A thorough understanding of the intracellular events that govern the IFN response will lay the foundation to identify the mechanisms that alter these effects during viral infection or malignant transformation.

\section{REFERENCES}

1.Abramovich, C., B. Yakobson, J. Chebath, and M. Revel. 1997. A proteinarginine methyltransferase binds to the intracytoplasmic domain of the IFNAR1 chain in the type I interferon receptor. EMBO J. 16:260-266.

2.Altschuler, L., J.O. Wook, D. Gurari, J. Chebath, and M. Revel. 1999. Involvement of receptor-bound protein methyltransferase PRMT1 in antiviral and antiproliferative effects of type I interferons. J. Interferon Cytokine Res. 19:189-195.
3.Barber, D.L., J.M. Mason, T. Fukazawa, K.A. Reedquist, B.J. Druker, H. Band, and A.D. D'Andrea. 1997. Erythropoietin and interleukin-3 activate tyrosine phosphorylation of CBL and association with CRK adaptor proteins. Blood 89.3166-3174.

4.Begitt, A., T. Meyer, M. van Rossum, and U. Vinkemeier. 2000. Nucleocytoplasmic translocation of Stat 1 is regulated by a leucine-rich export signal in the coiled-coil domain. Proc. Natl. Acad. Sci. USA 97:10418-10423.

5.Blesofsky, W.A., K. Mowen, R.M. Arduini, D.P. Baker, M.A. Murphy, D.D. Bowtell, and M. David. 2001. Regulation of STAT protein synthesis by cCbl. Oncogene 20:7326-7333.

6.Bromberg, J., C. Horvath, Z. Wen, R. Schreiber, and J. Darnell. 1996. Transcriptionally active Stat 1 is required for the antiproliferative effects of both interferon $\alpha$ and interferon $\gamma$. Proc. Natl. Acad. Sci. USA 93:76737678.

7.Chen, X., U. Vinkemeier, Y. Zhao, D. Jeruzalmi, J.E. Darnell, and J. Kuriyan. 1998. Crystal structure of a tyrosine phosphorylated STAT-1 dimer bound to DNA. Cell 93:827-839.

8.Chen, X.P., J.A. Losman, and P. Rothman. 2000. SOCS proteins, regulators of intracellular signaling. Immunity 13:287-290.

9.Cho, S.S., C.M. Bacon, C. Sudarshan, R.C. Rees, D. Finbloom, R. Pine, and J.J. O'Shea. 1996. Activation of STAT4 by IL-12 and IFN-alpha: evidence for the involvement of ligand-induced tyrosine and serine phosphorylation. J. Immunol. 157:4781-4789.

10.Chung, C.D., J. Liao, B. Liu, X. Rao, P. Jay, P. Berta, and K. Shuai. 1997. Specific inhibition of Stat 3 signal transduction by PIAS3. Science 278:18031805.

11.Colamonici, O.R., H. Uyttendaele, P. Domanski, and J.J. Krowleski. 1994. p135 tyk2, an interferon- $\alpha$-activated tyrosine kinase, is physically associated with an interferon- $\alpha$ receptor. J. Biol. Chem. 269.3518-3522.

12. David, M. and A.C. Larner. 1992. Activation of transcription factors by interferon alpha in a cell free system. Science 257:813-815.

13.David, M., P.M. Grimley, D.S. Finbloom, and A.C. Larner. 1993. A nuclear tyrosine phosphatase downregulates interferon-induced gene expression. Mol. Cell. Biol. 13:7515-7521.

14.David, M., G. Romero, Z.Y. Zhang, J.E. Dixon, and A.C. Larner. 1993. In vitro activation of the transcription factor ISGF3 by IFNo involves a membrane associated tyrosine phosphatase and kinase. J. Biol. Chem. 268:65936599.

15.David, M., H.E. Chen, S. Goelz, A.C. Larner, and B.G. Neel. 1995. Differential regulation of the IFN $\alpha / \beta$-stimulated Jak/Stat pathway by the $\mathrm{SH} 2$ domain containing tyrosine phosphatase SHPTP1. Mol. Cell. Biol. 15:7050-7058

16.David, M., E.F. Petricoin, III, C. Benjamin, R. Pine, M.J. Weber, and A.C. Larner. 1995. Requirement for MAP kinase (ERK2) activity in interferon $\alpha / \beta$-stimulated gene expression through Stat proteins. Science 269.1721 1723 .

17.David, M., G. Zhou, R. Pine, J.E. Dixon, and A.C. Larner. 1996. The SH2-domain containing tyrosine phosphatase PTP1D is required for IFN $\alpha / \beta$-induced gene expresssion. J. Biol. Chem. 271:15862-15865.

18.de Jong, R., J. ten Hoeve, N. Heisterkamp, and J. Groffen. 1995. Crkl is complexed with tyrosine-phosphorylated $\mathrm{Cbl}$ in Ph-positive leukemia. J. Biol. Chem. 270:21468-21471.

19.Domanski, P., M. Witte, M. Kellum, M. Rubinstein, R. Hackett, P. Pitha, and O.R. Colamonici. 1995. Cloning and expression of a long form of the $\beta$-subunit of the interferon $\alpha / \beta$ receptor that is required for signaling. J. Biol. Chem. 270:21606-21611.

20.Domanski, P., E. Fish, O.W. Nadeau, M. Witte, L.C. Platanias, H. Yan, J. Krolewski, P. Pitha, and O.R. Colamonici. 1997. A region of the beta subunit of the interferon alpha receptor different from box 1 interacts with Jak1 and is sufficient to activate the Jak-Stat pathway and induce an antiviral state. J. Biol. Chem. 272:26388-26393.

21.Durbin, J.E., R. Hackenmiller, M.C. Simon, and D.E. Levy. 1996. Targeted disruption of the mouse Stat 1 gene results in compromised innate immunity to viral disease. Cell 84:443-450.

22.Exley, R., J. Gordon, P. Nathan, L. Walker, and M.J. Clemens. 1987. Antiproliferative effects of interferons on Daudi Burkitt lymphoma cells: induction of cell differentiation and loss of response to autocrine growth factors. Int. J. Cancer 40:53-57.

23.Fasler-Kan, E., A. Pansky, M. Wiederkehr, M. Battegay, and M.H. Heim. 1998. Interferon-alpha activates signal transducers and activators of transcription 5 and 6 in Daudi cells. Eur. J. Biochem. 254:514-519.

24.Fish, E.N., S. Uddin, M. Korkmaz, B. Majchrzak, B.J. Druker, and L.C. 
Platanias. 1999. Activation of a CrkL-stat 5 signaling complex by type I in terferons. J. Biol. Chem. 274:571-573.

25.Fu, X.-Y., D.S. Kessler, S.A. Veals, D.E. Levy, and J.E. Darnell, Jr. 1990. ISGF-3, the transcriptional activator induced by IFN- $\alpha$, consists of multiple interacting polypeptide chains. Proc. Natl. Acad. Sci. USA 87:8555-8559.

26.Fu, X.-Y. 1992. A transcription factor with SH2 and SH3 domains is directly activated by an interferon- $\alpha$ induced cytoplasmic protein tyrosine kinase(s). Cell 70:323-335.

27.Fu, X.-Y., C. Schindler, T. Improta, R. Aebersold, and J.E.J. Darnell. 1992. The proteins of ISGF-3, the interferon $\alpha$-induced transcriptional activator, define a gene family involved in signal transduction. Proc. Natl. Acad. Sci. USA 89.7840-7843

28.Fu, X.-Y. and J.-J. Zhang. 1993. Transcription factor p91 interacts with the epidermal growth factor receptor and mediates activation of the $c$-fos gene promoter. Cell 74:1135-1145.

29.Gibbs, V.C., M. Takahashi, M. Aguet, and A. Chuntharapai. 1996. A negative regulatory region in the intracellular domain of the human interferon-alpha receptor. J. Biol. Chem. 271:28710-28716.

30.Goh, K.C., S.J. Haque, and B.R. Williams. 1999. p38 MAP kinase is required for STAT1 serine phosphorylation and transcriptional activation induced by interferons. EMBO J. 18:5601-5608.

31.Haque, S.J. and B.R.G. Williams. 1994. Identification and characterization of an interferon (IFN)-stimulated response element-IFN-stimulated gene factor 3-independent signaling pathway for IFN- $\alpha$. J. Biol. Chem. 269.19523-19529.

32.Haspel, R.L. and J.E. Darnell, Jr. 1999. A nuclear protein tyrosine phosphatase is required for the inactivation of Stat1. Proc. Natl. Acad. Sci. USA 96:10188-10193.

33.Heim, M.H., I.M. Kerr, G.R. Stark, and J.E. Darnell, Jr. 1995. Contribution of STAT SH2 groups to specific interferon signaling by the Jak-STAT pathway. Science 267:1347-1349.

34.Hilton, D.J. 1999. Negative regulators of cytokine signal transduction. Cell. Mol. Life Sci. 55:1568-1577.

35.Horvai, A.E., L. Xu, E. Korzus, G. Brard, D. Kalafus, T.-M. Mullen, D.W. Rose, M.G. Rosenfeld, and C.K. Glass. 1997. Nuclear integration of JAK/STAT and Ras/AP-1 signaling by CBP and p300. Proc. Natl. Acad. Sci. USA 94:1074-1079.

36.Horvath, C.M., Z. Wen, and J.E. Darnell, Jr. 1995. A STAT protein domain that determines DNA sequence recognition suggests a novel DNAbinding domain. Genes Dev. 9:984-994.

37.Isaacs, A., and J. Lindenmann. 1957. Virus interference. The Interferon. Proc. R. Soc. Lond. B Biol. Sci. 147:258-267.

38.Kawamura, M., D.W. McVicar, J.A. Johnston, T.B. Blake, Y.-Q. Chen, B.K. Lal, A.R. Lloyd, D.J. Kelvin, E. Staples, J.R. Ortaldo, and J.J. O'Shea. 1994. Molecular cloning of L-JAK, a Janus family protein-tyrosine kinase expressed in natural killer cells and activated leukocytes. Proc. Natl. Acad. Sci. USA 91:6374-6378.

39. Kessler, D.S., S.A. Veals, X.-Y. Fu, and D.S. Levy. 1990. Interferon- $\alpha$ regulates nuclear translocation and DNA-binding affinity of ISGF3, a multimeric transcriptional activator. Genes Dev. 4:1753-1765.

40.Kile, B.T., B.A. Schulman, W.S. Alexander, N.A. Nicola, H.M. Martin, and D.J. Hilton. 2002. The SOCS box: a tale of destruction and degradation. Trends Biochem Sci. 27:235-241.

41.Kim, T.K. and T. Maniatis. 1996. Regulation of interferon- $\gamma$-activated STAT1 by the ubiquitin-proteasome pathway. Science 273:1717-1719.

42.Knight, E., Jr., E.D. Anton, D. Fahey, B.K. Friedland, and G.J. Jonak. 1985. Interferon regulates c-myc gene expression in Daudi cells at the posttranscriptional level. Proc. Natl. Acad. Sci. USA 82:1151-1154.

43.Kotaja, N., U. Karvonen, O.A. Janne, and J.J. Palvimo. 2002. PIAS proteins modulate transcription factors by functioning as SUMO-1 ligases. Mol. Cell. Biol. 22:5222-5234.

44.Larner, A.C., M. David, G.M. Feldman, K. Igarashi, R.H. Hackett, D.A.S. Webb, S.M. Sweitzer, E.F. Petricoin, III, and D.S. Finbloom. 1993. Tyrosine phosphorylation of DNA binding proteins by multiple cytokines. Science 261:1730-1733.

45.Larner, A.C. and D.S. Finbloom. 1995. Protein tyrosine phosphorylation as a mechanism which regulates cytokine activation of early response genes. Biochim. Biophys. Acta 1266:278-287.

46.Lengyel, P. 1982. Biochemistry of interferons and their actions. Annu. Rev. Biochem. 51:251-285.

47.Leung, S., S. Qureshi, I. Kerr, J. Darnell, and G. Stark. 1995. Role of STAT2 in the alpha interferon signaling pathway. Mol. Cell. Biol. 15:1312-
1317.

48.Levy, D., A. Larner, A. Chauduri, L.E. Babiss, and J.E. Darnell, Jr. 1986. Interferon-stimulated transcription: isolation of an inducible gene and identification of its regulatory region. Proc. Natl. Acad. Sci. USA 83:8929-8933.

49.Levy, D.E., D.S. Kessler, R. Pine, N. Reich, and J.E. Darnell. 1988. Interferon-induced nuclear factors that bind a shared promoter element correlate with positive and negative transcriptional control. Genes Dev. 2:383-393.

50.Levy, D.E., D.S. Kessler, R. Pine, and J.E. Darnell, Jr. 1989. Cytoplasmic activation of ISGF3, the positive regulator of interferon- $\alpha$-stimulated transcription, reconstituted in vitro. Genes Dev. 3:1362-1371.

51.Levy, D.E., D.J. Lew, D.S. Kessler, and J.E. Darnell, Jr. 1990. Synergistic interaction between interferon- $\alpha$ and interferon- $\gamma$ through induced synthesis of one subunit of the transcription factor ISGF3. EMBO J. 9:1105-1111.

52.Lew, D.J., T. Decker, I. Strehlow, and J.E. Darnell. 1991. Overlapping elements in the guanylate-binding protein gene promoter mediate transcriptional induction by alpha and gamma interferons. Mol. Cell. Biol. 11:182191.

53.Li, X., S. Leung, I. Kerr, and G. Stark. 1997. Functional subdomains of STAT2 required for preassociation with the alpha interferon receptor and for signaling. Mol. Cell. Biol. 17:2048-2056.

54.Liu, B., J. Liao, X. Rao, S.A. Kushner, C.D. Chung, D.D. Chang, and K. Shuai. 1998. Inhibition of Stat1-mediated gene activation by PIAS1. Proc. Natl. Acad. Sci. USA 95:10626-10631.

55.Look, D.C., W.T. Roswit, A.G. Frick, Y. Gris-Alevy, D.M. Dickhaus, M.J. Walter, and M.J. Holtzman. 1998. Direct suppression of Stat1 function during adenoviral infection. Immunity 9:871-880.

56.Lutfalla, G., S.J. Holland, E. Cinato, D. Monneron, J. Reboul, N.C. Rogers, J.M. Smith, G.R. Stark, K. Gardiner, K.E. Mogensen, et al. 1995. Mutant U5A cells are complemented by an interferon-alpha beta receptor subunit generated by alternative processing of a new member of a cytokine receptor gene cluster. EMBO J. 14:5100-5108.

57.McBride, K.M., C. McDonald, and N.C. Reich. 2000. Nuclear export sig nal located within the DNA-binding domain of the STAT1 transcription factor. EMBO J. 19:6196-6206.

58.McMahon, M., G.R. Stark, and I.M. Kerr. 1986. Interferon-induced gene expression in wild-type and interferon-resistant human lymphoblastoid (Daudi) cells. J. Virol. 57:362-366.

59.Meinke, A., F. Barahmand-Pour, S. Wohrl, D. Stoiber, and T. Decker. 1996. Activation of different $S$ tat 5 isoforms contributes to cell-type- restricted signaling in response to interferons. Mol. Cell. Biol. 16:6937-6944.

60.Meraz, M.A., J.M. White, K.C.F. Sheehan, E.A. Bach, S.J. Rodig, A.S. Dighe, D.H. Kaplan, J.K. Riley, A.C. Greenlund, D. Campbell, et al. 1996 Targeted disruption of the Stat 1 gene in mice reveals unexpected physiologic specificity in the JAK-STAT signaling pathway. Cell 84:431-442.

61.Micouin, A., J. Wietzerbin, V. Steunou, and M.C. Martyre. 2000. p95(vav) associates with the type I interferon (IFN) receptor and contributes to the antiproliferative effect of IFN-alpha in megakaryocytic cell lines. Oncogene 19:387-394.

62.Mowen, K.A. and M. David. 1998. Role of the STAT1-SH2 domain and STAT2 in the nuclear translocation of STAT1. J. Biol. Chem. 273:3007330076.

63. Mowen, K., and M. David. 2000. Regulation of STAT1 nuclear export by Jak1. Mol. Cell. Biol. 20:7273-7281.

64.Mowen, K.A., J. Tang, W. Zhu, B.T. Schurter, K. Shuai, H.R. Herschman, and M. David. 2001. Arginine methylation of STAT1 modulates IFNalpha/beta-induced transcription. Cell 104:731-741.

65.Muller, M., C. Laxton, J. Briscoe, C. Schindler, T. Improta, J.E. Darnell, Jr., G.R. Stark, and I.M. Kerr. 1993. Complementation of a mutant cell line: central role of the $91 \mathrm{kD}$ a polypeptide of ISGF3 in the interferon- $\alpha$ and $-\gamma$ signal transduction pathways. EMBO J. 12:4221-4228.

66. Muller, M., J. Briscoe, C. Laxton, D. Guschin, A. Ziemiecki, O. Silvennoinen, A.G. Harpur, G. Barbieri, B.A. Withuhn, C. Schindler, et al. 1993. The protein tyrosine kinase JAK1 complements defects in the interferon- $\alpha / \beta$ and $-\gamma$ signal transduction. Nature 366:129-135.

67.Nadeau, O.W., P. Domanski, A. Usacheva, S. Uddin, L.C. Platanias, P. Pitha, R. Raz, D. Levy, B. Majchrzak, E. Fish, and O.R. Colamonici. 1999. The proximal tyrosines of the cytoplasmic domain of the beta chain of the type I interferon receptor are essential for signal transducer and activator of transcription (Stat) 2 activation. Evidence that two Stat 2 sites are required to reach a threshold of interferon alpha-induced Stat 2 tyrosine phosphorylation that allows normal formation of interferon-stimulated gene factor 3. J. Biol. Chem. 274:4045-4052. 


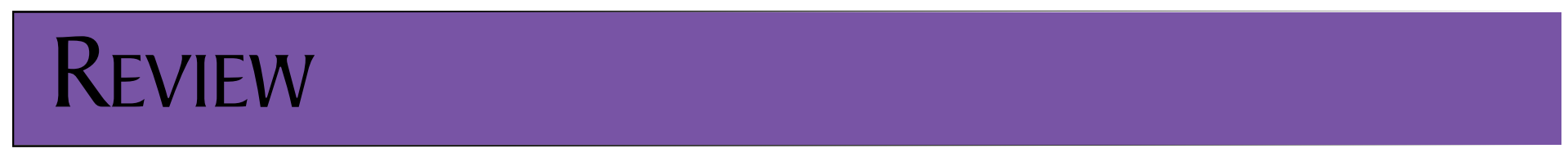

68.Nair, J.S., C.J. DaFonseca, A. Tjernberg, W. Sun, J.E. Darnell, Jr., B.T. Chait, and J.J. Zhang. 2002. Requirement of Ca2+ and CaMKII for Stat1 Ser-727 phosphorylation in response to IFN-gamma. Proc. Natl. Acad. Sci. USA 99.5971-5976.

69.Nguyen, H., C.V. Ramana, J. Bayes, and G.R. Stark. 2001. Roles of phosphatidylinositol 3-kinase in interferon-gamma-dependent phosphorylation of STAT1 on serine 727 and activation of gene expression. J. Biol. Chem. 276.33361-33368.

70.Novick, D., B. Cohen, and M. Rubinstein. 1994. The human interferon $\alpha / \beta$ receptor: characterization and molecular cloning. Cell 77:391-400.

71.Pearse, R.N., R. Feinman, K. Shuai, J.E. Darnell, Jr., and J.V. Ravetch. 1993. Interferon $\gamma$-induced transcription of the high-affinity Fc receptor for IgG requires assembly of a complex that includes the $91-\mathrm{kDa}$ subunit of transcription factor ISGF3. Proc. Natl. Acad. USA 90:4314-4318.

72.Pellegrini, S., J. John, M. Shearer, I.M. Kerr, and G.R. Stark. 1989. Use of a selectable marker regulated by alpha interferon to obtain mutations in the signaling pathway. Mol. Cell. Biol. 9:4605-4612.

73.Pestka, S., J.A. Langer, K.C. Zoon, and C.E. Samuel. 1987. Interferons and their actions. Annu. Rev. Biochem. 56:727-777.

74.Pestka, S. 2000. The human interferon alpha species and receptors. Biopolymers 55:254-287.

75.Petricoin, E.F., 3rd, S. Ito, B.L. Williams, S. Audet, L.F. Stancato, A. Gamero, K. Clouse, P. Grimley, A. Weiss, J. Beeler, D.S. Finbloom, E.W. Shores, R. Abraham, and A.C. Larner. 1997. Antiproliferative action of interferon-alpha requires components of T-cell-receptor signalling. Nature 390.629-632.

76.Pfeffer, L.M., J.E. Mullersman, S.R. Pfeffer, A. Murti, W. Shi, and C.H. Yang. 1997. STAT3 as an adapter to couple phosphatidylinositol 3-kinase to the IFNAR1 chain of the type I interferon receptor. Science 276:1418-1420.

77.Platanias, L.C. and M.E. Sweet. 1994. Interferon $\alpha$ induces rapid tyrosine phosphorylation of the vav proto-oncogene product in hematopoietic cells. J. Biol. Chem. 269:3143-3146.

78.Platanias, L.C., S. Uddin, P. Domanski, and O.R. Colamonici. 1996. Differences in interferon alpha and beta signaling. Interferon beta selectively induces the interaction of the alpha and betaL subunits of the type I interferon receptor. J. Biol. Chem. 271:23630-23633.

79.Platanias, L.C., S. Uddin, A. Yetter, X.J. Sun, and M.F. White. 1996. The type I interferon receptor mediates tyrosine phosphorylation of insulin receptor substrate 2. J. Biol. Chem. 271:278-282.

80.Platanias, L.C., S. Uddin, E. Bruno, M. Korkmaz, S. Ahmad, Y. Alsayed, D. Van Den Berg, B.J. Druker, A. Wickrema, and R. Hoffman. 1999. CrkL and CrkII participate in the generation of the growth inhibitory effects of interferons on primary hematopoietic progenitors. Exp. Hematol. 27:13151321.

81.Pollack, B.P., S.V. Kotenko, W. He, L.S. Izotova, B.L. Barnoski, and S. Pestka. 1999. The human homologue of the yeast proteins Skb1 and Hsl7p interacts with Jak kinases and contains protein methyltransferase activity. J. Biol. Chem. 274:31531-31542.

82.Rani, M.R., G.R. Foster, S. Leung, D. Leaman, G.R. Stark, and R.M. Ransohoff. 1996. Characterization of beta-R1, a gene that is selectively induced by interferon beta (IFN- $\beta$ ) compared with IFN-alpha. J. Biol. Chem. 271:22878-22884.

83.Rani, M.R., D.W. Leaman, Y. Han, S. Leung, E. Croze, E.N. Fish, A. Wolfman, and R.M. Ransohoff. 1999. Catalytically active TYK2 is essential for interferon-beta-mediated phosphorylation of STAT3 and interferon-alpha receptor-1 (IFNAR-1) but not for activation of phosphoinositol 3-kinase. J. Biol. Chem. 274:32507-32511.

84.Rani, M.R., A.R. Asthagiri, A. Singh, N. Sizemore, S.S. Sathe, X. Li, J.D. DiDonato, G.R. Stark, and R.M. Ransohoff. 2001. A role for NF-kappa B in the induction of beta-R1 by interferon-beta. J. Biol. Chem. 276:4436544368.

85. Reedquist, K.A., T. Fukazawa, G. Panchamoorthy, W.Y. Langdon, S.E. Shoelson, B.J. Druker, and H. Band. 1996. Stimulation through the T cell receptor induces $\mathrm{Cbl}$ association with Crk proteins and the guanine nucleotide exchange protein C3G. J. Biol. Chem. 271:8435-8442.

86. Reich, N., B. Evans, D.E. Levy, D. Fahey, E. Knight, and J.E. Darnell, Jr. 1987. Interferon-induced transcription of a gene encoding a $15-\mathrm{kDa}$ protein depends on an upstream enhancer element. Proc. Natl. Acad. Sci. USA 84:6394-6398.

87.Reich, N.C. and J.E. Darnell. 1989. Differential binding of interferon-induced factors to an oligonucleotide that mediates transcriptional activation. Nucleic Acids Res. 17:3415-3424
88. Rogge, L., D. D’Ambrosio, M. Biffi, G. Penna, L.J. Minetti, D.H. Presky, L. Adorini, and F. Sinigaglia. 1998. The role of Stat 4 in species-specific regulation of Th cell development by type I IFNs. J. Immunol. 161:6567-6574.

89.Sakatsume, M., L.F. Stancato, M. David, O. Silvennoinen, P. Saharinen, J. Pierce, A.C. Larner, and D.S. Finbloom. 1998. Interferon gamma activation of Raf-1 is Jak1-dependent and p21ras- independent. J. Biol. Chem. 273:3021-3026.

90.Schindler, C., K. Shuai, V.R. Prezioso, and J.E.J. Darnell. 1992. Interferondependent tyrosine phosphorylation of a latent transcription factor. Science 257:809-813.

91.Schindler, C., X.-Y. Fu, T. Improta, R. Aebersold, and D.J.E. Jr. 1992. Proteins of transcription factor ISGF-3: one gene encodes the 91 - and $84-\mathrm{kDa}$ ISGF-3 proteins that are activated by interferon $\alpha$. Proc. Natl. Acad. Sci. USA 89.7836-7839.

92.Schmidt, D. and S. Muller. 2002. Members of the PIAS family act as SUMO ligases for c-Jun and p53 and repress p 53 activity. Proc. Natl. Acad. Sci. USA 99.2872-2877.

93.Sekimoto, T., K. Nakajima, T. Tachibana, T. Hirano, and Y. Yoneda. 1996. Interferon- $\gamma$-dependent nuclear import of Stat 1 is mediated by the GTPase activity of Ran/TC4. J. Biol. Chem. 271:31017-31020.

94.Sekimoto, T., N. Imamoto, K. Nakajima, T. Hirano, and Y. Yoneda. 1997. Extracellular signal-dependent nuclear import of Stat1 is mediated by nuclear pore-targeting complex formation with NPI-1, but not Rch1. EMBO J. 16:7067-7077.

95.Shuai, K., G.R. Stark, I.M. Kerr, and J.E. Darnell, Jr. 1993. A single phosphotyrosine residue of Stat91 required for gene activation by interferon $\gamma$ Science 261:1744-1746.

96.Shuai, K., C.M. Horvath, L.H. Tsai Huang, S.A. Qureshi, D. Cowburn, and J. Darnell. 1994. Interferon activation of the transcription factor Stat91 involves dimerization through $\mathrm{SH} 2$-phosphotyrosyl peptide interactions. Cell 76:821-828.

97.Smit, L., G. van der Horst, and J. Borst. 1996. Sos, Vav, and C3G participate in B cell receptor-induced signaling pathways and differentially associate with Shc-Grb2, Crk, and Crk-L adaptors. J. Biol. Chem. 271:8564-8569.

98.Stancato, L., M. Sakatsume, M. David, P. Dent, F. Dong, E. Petricoin, J. Krolewski, O. Silvennoinen, P. Saharinen, J. Pierce, C. Marshall, T. Sturgill, D. Finbloom, and A. Larner. 1997. Beta interferon and oncostatin $\mathrm{M}$ activate Raf-1 and mitogen activated protein kinase through a JAK1-dependent pathway. Mol. Cell. Biol. 17:3833-3840.

99.Stancato, L.F., C.R. Yu, E.F. Petricoin, 3rd, and A.C. Larner. 1998. Activation of Raf-1 by interferon gamma and oncostatin $\mathrm{M}$ requires expression of the Stat1 transcription factor. J. Biol. Chem. 273:18701-18704.

100.Stark, G.R., I.M. Kerr, B.R. Williams, R.H. Silverman, and R.D. Schreiber. 1998. How cells respond to interferons. Annu. Rev. Biochem. 67:227-264

101.Su, L., and M. David. 2000. Distinct mechanisms of STAT phosphorylation via the interferon- alpha/beta receptor. Selective inhibition of STAT3 and STAT5 by piceatannol. J. Biol. Chem. 275:12661-12666.

102.Tanaka, S., T. Morishita, Y. Hashimoto, S. Hattori, S. Nakamura, M. Shibuya, K. Matuoka, T. Takenawa, T. Kurata, K. Nagashima, et al. 1994. C3G, a guanine nucleotide-releasing protein expressed ubiquitously, binds to the Src homology 3 domains of CRK and GRB2/ASH proteins. Proc. Natl. Acad. Sci. USA 91:3443-3447.

103.Taniguchi, T., H. Harada, and M. Lamphier. 1995. Regulation of the interferon system and cell growth by the IRF transcription factors. J. Cancer Res. Clin. Oncol. 121:516-520.

104.Taniguchi, T. 1995. IRF-1 and IRF-2 as regulators of the interferon system and cell growth. Indian J. Biochem. Biophys. 32:235-239.

105.ten Hoeve, J., M.J. Ibarra-Sanchez, Y. Fu, W. Zhu, M. Tremblay, M. David, and K. Shuai. 2002. Identification of a nuclear Stat1 protein tyrosine phosphatase. Mol. Cell. Biol. 22:5662-5668.

106.Tiefenbrun, N., D. Melamed, N. Levy, D. Resnitzky, I. Hoffman, S. Reed, and A. Kimchi. 1996. Alpha interferon suppresses the cyclin D3 and $c d c 25 A$ genes leading to a reversible $\mathrm{G}_{\mathrm{o}}$-like arrest. Mol. Cell. Biol. 16:39343944.

107.Uddin, S., L. Yenush, X.-J. Sun, M.E. Sweet, M.F. White, and L.C. Plata nias. 1995. Interferon- $\alpha$ engages the insulin receptor substrate-1 to associate with the phosphatidylinositol 3'-kinase. J. Biol. Chem. 270:15938-15941.

108.Uddin, S., C. Gardziola, A. Dangat, T. Yi, and L.C. Platanias. 1996. Interaction of the c-cbl proto-oncogene product with the Tyk-2 protein tyrosine kinase. Biochem. Biophys. Res. Commun. 225:833-838.

109.Uddin, S., D.A. Sher, Y. Alsayed, S. Pons, O.R. Colamonici, E.N. Fish, 
M.F. White, and L.C. Platanias. 1997. Interaction of p59fyn with interferon-activated Jak kinases. Biochem. Biophys. Res. Commun. 235:83-88.

110.Uddin, S., M. Sweet, O.R. Colamonici, J.J. Krolewski, and L.C. Platanias. 1997. The vav proto-oncogene product (p95vav) interacts with the Tyk-2 protein tyrosine kinase. FEBS Lett. 403:31-34.

111.Uddin, S., B. Majchrzak, J. Woodson, P. Arunkumar, Y. Alsayed, R. Pine, P.R. Young, E.N. Fish, and L.C. Platanias. 1999. Activation of the p38 mitogen-activated protein kinase by type I interferons. J. Biol. Chem. 274:30127-30131.

112.Uddin, S., B. Majchrzak, P.C. Wang, S. Modi, M.K. Khan, E.N. Fish, and L.C. Platanias. 2000. Interferon-dependent activation of the serine kinase PI 3 -kinase requires engagement of the IRS pathway but not the Stat pathway. Biochem. Biophys. Res. Commun. 270.158-162.

113.Uddin, S., A. Sassano, D.K. Deb, A. Verma, B. Majchrzak, A. Rahman, A.B. Malik, E.N. Fish, and L.C. Platanias. 2002. Protein kinase C-delta (PKC- $\Delta$ ) is activated by type I interferons and mediates phosphorylation of Stat1 on serine 727. J. Biol. Chem. 277:14408-14416.

114.Uze, G., G. Lutfalla, and I. Gresser. 1990. Genetic transfer of a functional interferon $\alpha$ receptor into mouse cells: cloning and expression of its cDNA. Cell 60:225-234.

115.Velazquez, L., M. Fellous, G.R. Stark, and S. Pellegrini. 1992. A protein tyrosine kinase in the interferon $\alpha / \beta$ signaling pathway. Cell 70:313-322.

116.Wen, Z., Z. Zhong, and J.E. Darnell, Jr. 1995. Maximal activation of transcription by Stat 1 and Stat 3 requires both tyrosine and serine phosphorylation. Cell 82:241-250.

117.Williams, A.R., S. Lanker, E.E. Patton, K.L. Craig, T.F. Nason, N. Mathias, R. Kobayashi, C. Wittenberg, and M. Tyers. 1996. Cdc53 Targets phosphorylated G1 cyclins for degradation by the ubiquitin proteolytic pathway. Cell 86:453-463.

118Xu, X., Y.L. Sun, and T. Hoey. 1996. Cooperative DNA binding and sequence-selective recognition conferred by the STAT amino-terminal domain. Science 273:794-797.

119.Yang, C.H., A. Murti, and L.M. Pfeffer. 1998. STAT3 complements defects in an interferon-resistant cell line: evidence for an essential role for STAT3 in interferon signaling and biological activities. Proc. Natl. Acad. Sci. USA 95:5568-5572.

120.Yang, C.H., A. Murti, S.R. Pfeffer, L. Basu, J.G. Kim, and L.M. Pfeffer. 2000. IFNalpha /beta promotes cell survival by activating NF-kappa B. Proc. Natl. Acad. Sci. USA 97:13631-13636.

121.You, M., D.H. Yu, and G.S. Feng. 1999. Shp-2 tyrosine phosphatase functions as a negative regulator of the interferon-stimulated Jak/STAT pathway. Mol. Cell. Biol. 19:2416-2424.

122.Zhang, J.J., Y. Zhao, B.T. Chait, W.W. Lathem, M. Ritzi, R. Knippers, and J.E. Darnell, Jr. 1998. Ser727-dependent recruitment of MCM5 by Statlalpha in IFN-gamma-induced transcriptional activation. EMBO J. 17:6963-6971.

123.Zhu, M., S. John, M. Berg, and W.J. Leonard. 1999. Functional association of Nmi with Stat 5 and Stat 1 in IL-2- and IFNgamma-mediated signating. Cell 96:121-130.

\section{Address correspondence to:}

Dr. Michael David

Division of Biological Sciences and UCSD Cancer Center

Bonner Hall 3138

9500 Gilman Drive

La Jolla, CA 92093-0322

e-mail:midavid@ucsd.edu 